\title{
Higher IL-8 Response to Mycobacterium tuberculosis Antigens in Women above 40 Years
}

\author{
Marielle Leboueny $^{1 *}$, Priscillia Virginie Liesse Mbourou Mensah ${ }^{2 *}$, Paulin N. Essone ${ }^{3}$, \\ Anicet Christel Maloupazoa Siawaya ${ }^{1}$, Amel Kévin Alame-Emane ${ }^{4}$, Amandine Mveang Nzoghe ${ }^{1}$, \\ Dimitri Ulrich Essamazokou', Carene Anne Ndong Sima5, Ofilia Mvoundza Ndjindji, \\ Guy-Stéphane Padzys', Joseph Privat Ondo33, Brigitte Gicquel7, Joel Fleury Djoba Siawaya1,4\#
}

\author{
${ }^{1}$ Service Laboratoire, Centre Hospitalier Universitaire Mère Enfant Fondation Jeanne EBORI, Libreville, Gabon \\ ${ }^{2}$ Département de chimie, Faculté des Sciences, Université des Sciences et Techniques de Masuku, Franceville, Gabon \\ ${ }^{3}$ Centre de Recherches Médicales de Lambaréné, BP 242, Lambaréné, Gabon \\ ${ }^{4}$ Unité des Recherche et de Diagnostic Spécialisé, Laboratoire National de Santé Publique, Libreville, Gabon \\ ${ }^{5}$ Department of Biomedical Sciences, Division of Molecular Biology and Human Genetics, Faculty of Medicine and Health \\ Sciences, Stellenbosch University, Stellenbosch, South Africa \\ ${ }^{6}$ Département de Biologie, Faculté des Sciences, Université des Sciences et Techniques de Masuku, Franceville, Gabon \\ ${ }^{7}$ Unité de Génétique Mycobactérienne, Institut Pasteur, Paris, France \\ Email: "joel.djoba@gmail.com
}

How to cite this paper: Leboueny, M., Mensah, P.V.L.M., Essone, P.N., Siawaya, A.C.M., Alame-Emane, A.K., Nzoghe, A.M., Essamazokou, D.U., Sima, C.A.N., Ndjindji, O.M., Padzys, G.-S., Ondo, J.P., Gicquel, B. and Siawaya, J.F.D. (2021) Higher IL-8 Response to Mycobacterium tuberculosis Antigens in Women above 40 Years. Journal of Tuberculosis Research, 9, 266-275. https://doi.org/10.4236/jtr.2021.94025

Received: March 16, 2021

Accepted: November 7, 2021

Published: November 10, 2021

Copyright $\odot 2021$ by author(s) and Scientific Research Publishing Inc. This work is licensed under the Creative Commons Attribution International License (CC BY 4.0).

http://creativecommons.org/licenses/by/4.0/ (c) (i) Open Access

\begin{abstract}
Objective: Circulating levels of sex hormones vary with age. Moreover, there is emerging evidence supporting that sex hormones have an influence on the immune response of women. Here, we investigated age-associated levels of sex hormones and Mycobacterium tuberculosis (Mtb) specific cytokines response in women. Design: Using immunoassay methods, we have measured and compared secretion levels of E2, $\mathrm{P} 4$ and $M t b$ specific secretion of $11 \mathrm{cy}-$ tokines including Granulocyte-macrophage colony-stimulating factor (GMCSF), Interferon gamma (IFN- $\gamma$ ), Interleukin 1 beta (IL-1 $\beta$ ), IL-10, IL-12 (p70), IL-2, IL-4, IL-5, IL-6, IL-8, and Tumor necrosis factor (TNF- $\alpha$ ) in forty-two (42) HIV-negative females. Results: Estradiol (E2) and progesterone (P4) levels were significantly higher in younger women irrespective of their LTB status ( $\mathrm{p}<[0.0001-0.05])$. Mtb IL-8 specific response was significantly higher in women above 40 years old than in women under 40 years old. Conclusion: In premenopausal women, there is an increase in the pro-inflammatory cytokine IL-8 secretion in response to $M t b$-antigen. This observation suggests an underlying link between the pro-inflammatory cytokine and age associated hormonal changes, which may have implications on the course of tuberculosis infection women.
\end{abstract}




\section{Keywords}

IL-8, Mycobacterium tuberculosis, Estradiol (E2), Progesterone (P4)

\section{Introduction}

Tuberculosis (TB) kills more than 1.3 million lives worldwide each year according to the most recent World Health Organization (WHO) report [1]. It is believed that, roughly a third of the global population is latently infected with $M y$ cobacterium tuberculosis (Mtb); however, only 5 to 10 percent among them will progress to clinical disease [2], regardless of the host immunocompetency. Active TB infection has been associated with known identifiable factors such as (but not limited to) smoking, alcohol consumption, diabetes, age, gender, and HIV status [2]. While the mechanism of infection resulting from the association between some of the risk factors (i.e., smoking, alcoholism, diabetes, age, and HIV) and tuberculosis have been extensively studied and well documented, the same cannot be said for the relationship between gender status and TB risk as the exact mechanisms behind the association between the two remain ambiguous broad and warrant further explorations.

Studies have demonstrated gender inequality in immune responses and susceptibility to infections [3]-[8]. Regarding tuberculosis, it has been shown that host social behavioral and biological mechanisms may also contribute to gender inequality of infection risks [4] [9]. There is two-way communication between the immune and endocrine systems that facilitate and regulate the host responses during infections. Studies report different effects of estradiol (E2) and progesterone (P4) on the immune responses. It has been reported that E2 suppresses stimulated mononuclear cells cytokines production, whereas progesterone enhances it [10] [11]. The anti-inflammatory function of E2 and the proinflammatory action of P4 are documented [12] [13]. However, it has been reported that E2 and P4 exhibit both proinflammatory and anti-inflammatory responses in a dose- and context-dependent manner [14] [15] [16] [17]. In this study for which a preliminary version has been released as a pre-print at Research Square [18], we investigated the relationship between E2, P4 and cytokines response to $M t b$-antigens in women.

\section{Methods}

\section{Study design and participants}

From the Nkembo TB Specialized Hospital and the National Laboratory of Public Health in Libreville (Gabon), we recruited forty-two (42) HIV-negative females (17 LTB-infected and 25 LTB-negative) in a age-based case-control designed study. The exclusion criteria included any suggestion of active TB, previous history of active TB and any other clinical sign of disease including fever, weight loss, prolonged fatigue. All participants were screened with the Quanti- 
FERON-TB (QFT) Gold in-tube test, (QIAGEN-France), following the manufacturer's guidelines. Participants with positive tests were considered to have a latent TB infection (LTB).

Sample handling. Whole blood was collected from all study participants into QFT test tubes including the Nil, and $M t b$-antigen (ESAT-6/CFP-10/TB7.7) tubes. The tubes were then incubated overnight in a humidified incubator at $37^{\circ} \mathrm{C}$, with $5 \% \mathrm{CO}_{2}$. The following day, supernatants were harvested into aliquots and stored at $-40^{\circ} \mathrm{C}$.

Luminex analysis. Concentrations of 11 cytokines including Granulocyte-macrophage colony-stimulating factor (GM-CSF), Interferon gamma (IFN- $\gamma$ ), Interleukin 1 beta (IL-1 $\beta$ ), IL-10, IL-12 (p70), IL-2, IL-4, IL-5, IL-6, IL-8, and Tumor necrosis factor (TNF- $\alpha$ ) were measured on the Bio-Plex 200 bead array system (Bio-Rad Laboratories, USA) using the Procartaplex-11-plex kits (Life Technologies-Thermo Fisher Scientific-USA). Mtb-antigen induced cytokine concentrations were determined by subtracting baseline cytokines concentrations (from non-stimulated samples) from the concentration of cytokines measured in the TB-antigen stimulated samples.

Estradiol (E2) and progesterone (P4) analysis. The circulating levels of E2 and P4 were measured using Roche Diagnostics on the Cobas-e411 assay instrument (Roche Diagnostics Mannheim Germany).

Statistical analysis. The statistical analysis was performed using GraphPad Prism software version 6. The comparisons of the level of E2, P4, and cytokines between the groups of women were analyzed using the unpaired non-parametric test (Mann Whitney test). For all tests, the threshold of significance was a pvalue below 0.05 .

Ethics approval and consent to participate. The research was done following Gabonese ethical guidelines and regulations, and approval was obtained from the Gabonese National Laboratory of Public Health ethics committee. The Institute Pasteur Center for Translational Research open desk also approved the study.

\section{Results}

\section{Age distribution}

Participants were between the age of 21 and 62 (24 below 40 years of age (43\%) and 18 above 40 years of age (57\%)). In both LTB infected and LTB non-infected women groups, the age of participants were normally distributed (D’Agostino \& Pearson omnibus normality test passed) and the Mann-Whiney test showed no significant differences in age between LTB infected and LTB noninfected women (Figure 1).

Levels of estradiol (E2) and progesterone (P4) in LTB-infected and noninfected women

Both E2 and P4 levels were similar in LTB infected and LTB non-infected women (Figure 2(a) and Figure 2(b)). 


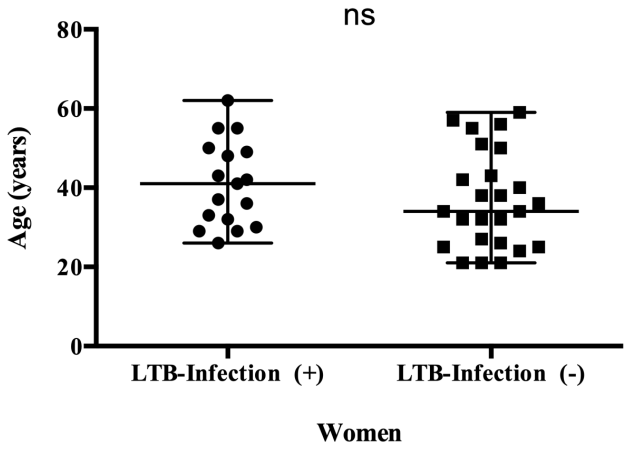

Figure 1. Age distribution of latent tuberculosis (LTB) infected and non-infected women. In the figures, bars indicate a median with ranges and ns means no significant differences between the groups.

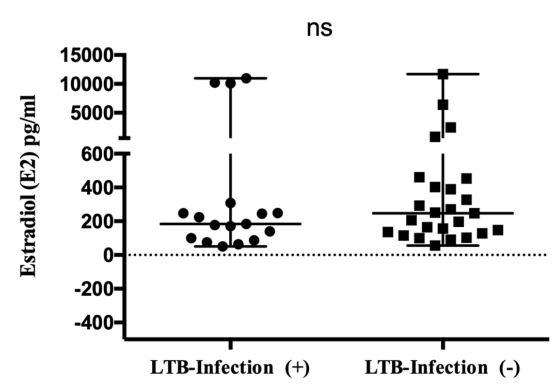

(a)

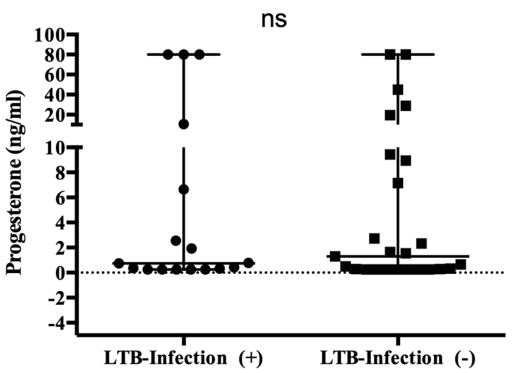

(b)

Women

Figure 2. Estradiol (a) and progesterone (b) concentrations in latent tuberculosis (LTB) infected and non-infected women. The bars in the graphs indicate median with range and ns means no significant differences between the groups.

\section{Age-based levels of estradiol (E2) and progesterone (P4)}

Both E2 and P4 levels were significantly higher in younger women (less than 40 years old) than in older women (above 40 years old) irrespective of their LTB status (p < [0.0001 - 0.05]) (Figure 3(a) and Figure 3(b)).

\section{Age-based cytokines response to Mtb antigens stimuli}

Of the 11 cytokines analyzed, $M t b$ antigens-induced IL-8 response was significantly higher in women above 40 years old than in younger women (Figure 4). No other significant differences in Mtb specific cytokines responses were observed (Figure 5). Also, no significant differences were observed between age groups in women non-infected by $M t b$.

\section{Discussion}

The present study showed women aged above 40 years had a significantly lower level of E2 and P4, an observation that may be age-related to their premenopausal statuses as sex hormones levels such as estradiol decline with advancing age.

In women under 40 years old, we observed a negative correlation between IL-8 response to $M t b$ antigens stimulation and both E2 and P4. Furthermore, the 


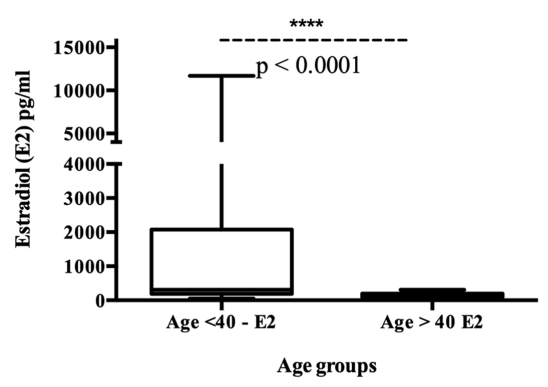

(a)

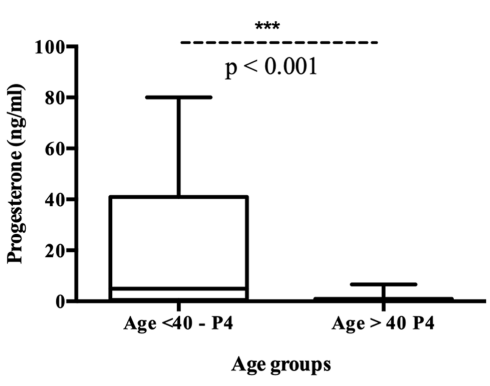

(b)

Figure 3. Age-based concentration estradiol (a) and progesterone (b). Women aged 40 and above had lower estradiol (E2) and progesterone (P4) than younger women. The difference between women aged below 40 years old and women aged 40 and above was analyzed using the Mann-Whitney $U$-test. The differences were considered significant for a p-value $<0.05$. In the figures, bars indicate medians and ranges.

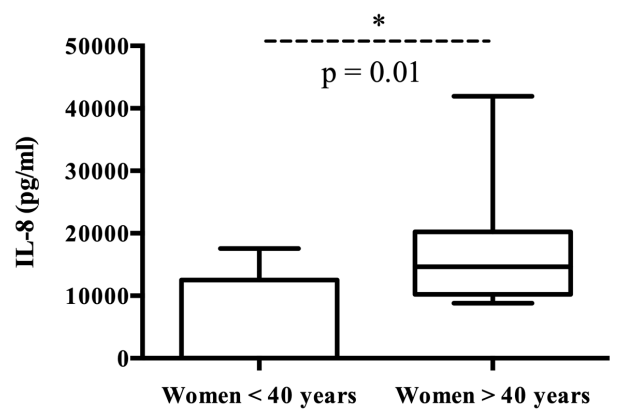

Figure 4. Age-based IL-8 response to $M t b$-antigen stimuli. Women aged 40 and above had higher IL-8 responses to $M t b$-antigen stimuli as compared to younger women. The differences were considered significant for a p-value $<0.05$.

higher IL-8 responses to M. tuberculosis antigens stimulation in women with lower levels of E2 and P4 (women above 40 years old) suggest that the reduced secretion of ovarian sex steroid hormones at a premenopausal age enhances proinflammatory response [19]. Menopause associated with high levels of proinflammatory cytokines (including IL-8) have been previously reported in the literature [20]. Relevant to tuberculosis, published data suggest that IL-8 not only increases the ability of neutrophils and macrophages to phagocyte and kill $M$. tuberculosis but also recruits T-lymphocytes [21] [22] [23].

The high IL-8 responses to M. tuberculosis antigens stimulation in women above 40 years with lower levels of E2 and P4 may explain why pre-and postmenopausal women are less susceptible to tuberculosis than women in their early reproductive age [24] [25]. However, the enhanced proinflammatory response of women aged above 40 years old may make them more prone to inflammatory disorders or chronic diseases [26] [27] [28].

The absence of data on participants' menstrual cycles would be the principal limit of this study. Indeed, the luteal phase of menstrual cycle is accompanied by hormonal changes (increased production of E2 and P4). Analysis based on the menstrual cycle of participants would have given more insight on women hormonal variation and immune response to tuberculosis. However, this does 


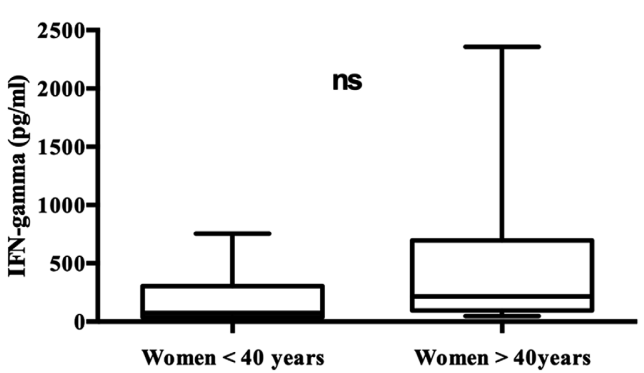

(a)

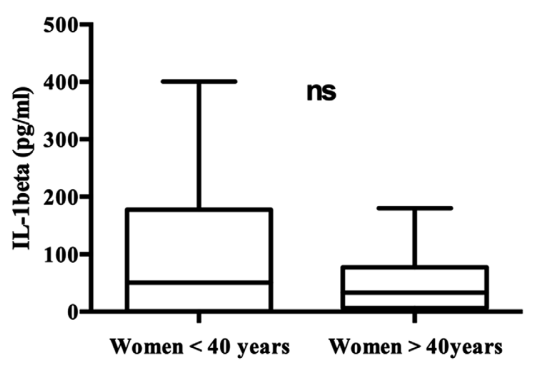

(c)

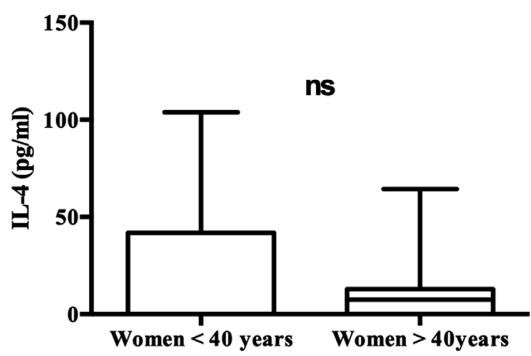

(e)

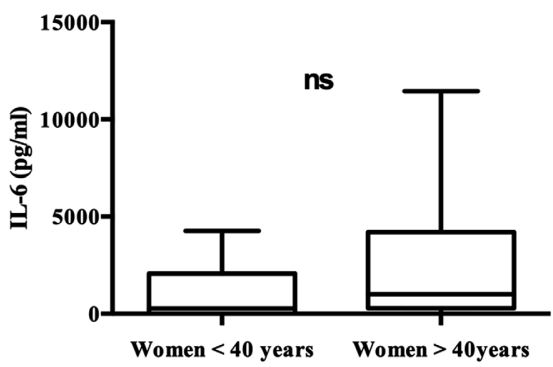

(g)

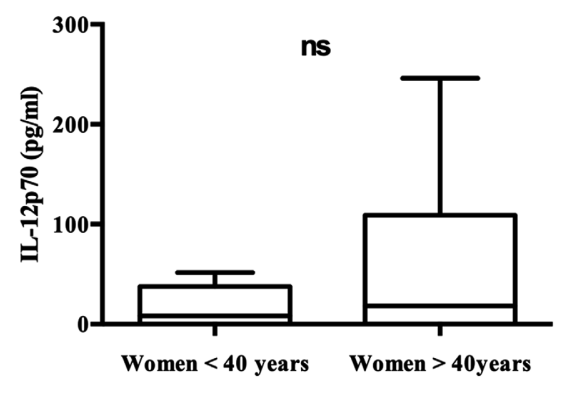

(i)

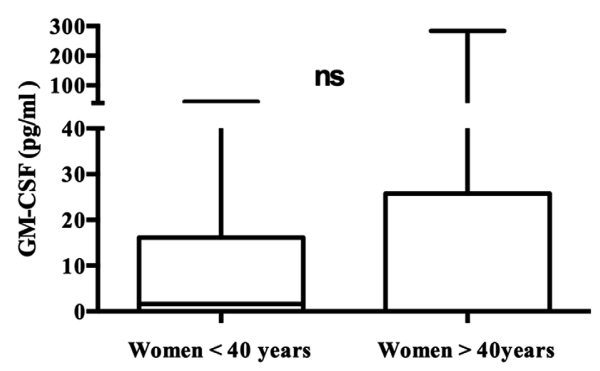

(b)

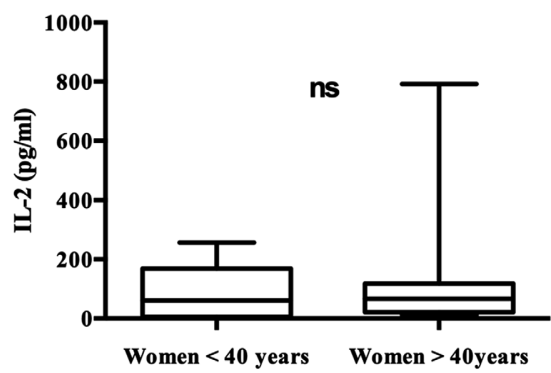

(d)
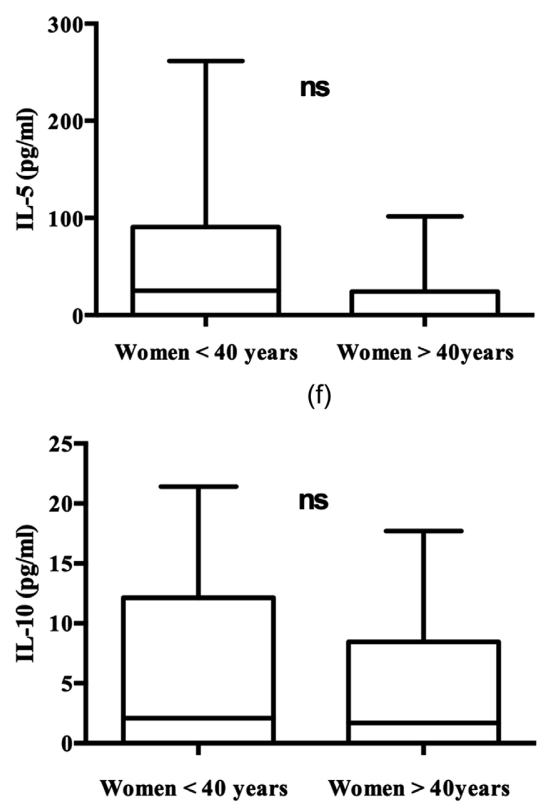

(h)

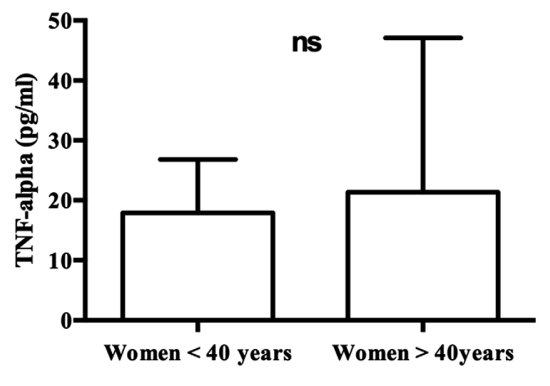

(j)

Figure 5. Age-based cytokines (GM-CSF, IFN- $\gamma$, IL-1 $\beta$, IL-2, IL-4, IL-5, IL-6, IL-10, IL-12 (p70), and TNFa) response to $M t b$-antigen stimuli. The differences were considered significant for a $\mathrm{p}$-value $<0.05$; ns means no significant differences between the groups. 
not affect the intrinsic link between hormone levels and cytokine responses. Also, the study can hardly establish if a spurious relationship or independent association drives the observed correlations between hormones and cytokines secretion. The complexity of the endocrine and immune system crosstalk put us in a relatively grey area when it comes to $\mathrm{E} 2$ and $\mathrm{P} 4$ influence on the immune system and its response to infections or immune disorders.

\section{Conclusion}

In premenopausal women, there is an increase in the pro-inflammatory cytokine IL-8 secretion in response to $M t b$-antigen, suggesting a link between the pro-inflammatory cytokine and age associated hormonal changes.

\section{Acknowledgements}

We thank all study participants and the Gabonese Government for funding the study. Also, a version of "This manuscript has been released as a pre-print at Research Square, [DOI: 10.21203/rs.3.rs-26657/v1]".

\section{Authors' Contributions}

J. F. D. S is the principal investigator who conceived, designed the study, did experiments, analyzed the data, and wrote the paper. BG is Co-investigator involved in the materialization of the study, organized, and participated in writing the manuscript. ML, VLMM, and PNE participated in study design samples processing and experiments. M. L, A. C. M. S, AKAE, OCAB, PHDT, AMN, DUE, OMN, and GSP helped in the recruitment of participants, acquisition of the samples, experiments, and the study organization. CANS participated in the critical analysis of data and writing of the manuscript.

\section{Conflicts of Interest}

The authors declare no competing financial or non-financial interests concerning the present work.

\section{Consent for Publication}

There is no material needing consent for publication.

\section{Availability of Data and Materials}

All materials described in the manuscript will be freely available on-demand to any scientist wishing to use them.

\section{Funding}

The Gabonese State through the Presidency of the Gabonese Republic.

\section{References}

[1] World Health Organization (2018) Global Tuberculosis Report 2018. World Health 
Organization, Geneva.

[2] World Health Organization (2017) Global Tuberculosis Report 2017. World Health Organization, Geneva.

[3] Feng, J.Y., Huang, S.F., Ting, W.Y., Chen, Y.C., Lin, Y.Y., Huang, R.M., Lin, C.H., Hwang, J.J., Lee, J.J., Yu, M.C., Yu, K.W., Lee, Y.C. and Su, W.J. (2012) Gender Differences in Treatment Outcomes of Tuberculosis Patients in Taiwan: A Prospective Observational Study. Clinical Microbiology and Infection, 18, E331-E337. https://doi.org/10.1111/j.1469-0691.2012.03931.x

[4] Neyrolles, O. and Quintana-Murci, L. (2009) Sexual Inequality in Tuberculosis. PLoS Medicine, 6, Article ID: e1000199. https://doi.org/10.1371/journal.pmed.1000199

[5] Yen, Y.F., Hu, H.Y., Lee, Y.L., Ku, P.W., Ko, M.C., Chuang, P.H., Lai, Y.J. and Chu, D. (2018) Sexual Inequality in Incident Tuberculosis: A Cohort Study in Taiwan. BMJ Open, 8, Article ID: e020142. https://doi.org/10.1136/bmjopen-2017-020142

[6] Essone, P.N., Leboueny, M., Maloupazoa Siawaya, A.C., Alame-Emane, A.K., Aboumegone Biyogo, O.C., Dapnet Tadatsin, P.H., Mveang Nzoghe, A., Essamazokou, D.U., Mvoundza Ndjindji, O., Padzys, G.S., Agnandji, S.T., Takiff, H., Gicquel, B. and Djoba Siawaya, J.F. (2019) M. tuberculosis Infection and Antigen Specific Cytokine Response in Healthcare Workers Frequently Exposed to Tuberculosis. Scientific Reports, 9, Article No. 8201. https://doi.org/10.1038/s41598-019-44294-0

[7] Klein, S.L. and Flanagan, K.L. (2016) Sex Differences in Immune Responses. Nature Reviews Immunology, 16, 626-638. https://doi.org/10.1038/nri.2016.90

[8] Gabriel, G. and Arck, P.C. (2014) Sex, Immunity and Influenza. Journal of Infectious Diseases, 209, S93-S99. https://doi.org/10.1093/infdis/jiu020

[9] Nhamoyebonde, S. and Leslie, A. (2014) Biological Differences between the Sexes and Susceptibility to Tuberculosis. Journal of Infectious Diseases, 209, S100-S106. https://doi.org/10.1093/infdis/jiu147

[10] Yuan, Y., Shimizu, I., Shen, M., Aoyagi, E., Takenaka, H., Itagaki, T., Urata, M., Sannomiya, K., Kohno, N., Tamaki, K., Shono, M. and Takayama, T. (2008) Effects of Estradiol and Progesterone on the Proinflammatory Cytokine Production by Mononuclear Cells from Patients with Chronic Hepatitis C. World Journal of Gastroenterology, 14, 2200-2207. https://doi.org/10.3748/wjg.14.2200

[11] Huang, H., He, J., Yuan, Y., Aoyagi, E., Takenaka, H., Itagaki, T., Sannomiya, K., Tamaki, K., Harada, N., Shono, M., Shimizu, I. and Takayama, T. (2008) Opposing Effects of Estradiol and Progesterone on the Oxidative Stress-Induced Production of Chemokine and Proinflammatory Cytokines in Murine Peritoneal Macrophages. Journal of Medical Investigation, 55, 133-141. https://doi.org/10.2152/jmi.55.133

[12] Schneider, A.H., Kanashiro, A., Dutra, S.G.V., Souza, R.D.N., Veras, F.P., Cunha, F.Q., Ulloa, L., Mecawi, A.S., Reis, L.C. and Malvar, D.D.C. (2019) Estradiol Replacement Therapy Regulates Innate Immune Response in Ovariectomized Arthritic Mice. International Immunopharmacology, 72, 504-510.

https://doi.org/10.1016/j.intimp.2019.04.048

[13] Shakya, R. and Chongthammakun, S. (2019) 17ß-Estradiol Attenuates the Influence of Chronic Activated Microglia on SH-SY5Y Cell Proliferation via Canonical WNT Signaling Pathway. Neuroscience Letters, 692, 174-180. https://doi.org/10.1016/j.neulet.2018.10.063

[14] Medina-Estrada, I., Alva-Murillo, N., Lopez-Meza, J.E. and Ochoa-Zarzosa, A. (2018) Immunomodulatory Effects of $17 \beta$-Estradiol on Epithelial Cells during Bacterial Infections. Journal of Immunology Research, 2018, Article ID: 6098961. https://doi.org/10.1155/2018/6098961 
[15] Kovats, S. (2015) Estrogen Receptors Regulate Innate Immune Cells and Signaling Pathways. Cellular Immunology, 294, 63-69.

https://doi.org/10.1016/j.cellimm.2015.01.018

[16] Calippe, B., Douin-Echinard, V., Laffargue, M., Laurell, H., Rana-Poussine, V., Pipy, B., Guery, J.C., Bayard, F., Arnal, J.F. and Gourdy, P. (2008) Chronic Estradiol Administration in Vivo Promotes the Proinflammatory Response of Macrophages to TLR4 Activation: Involvement of the Phosphatidylinositol 3-Kinase Pathway. Journal of Immunology, 180, 7980-7988. https://doi.org/10.4049/jimmunol.180.12.7980

[17] Arnal, J.F., Douin-Echinard, V., Tremollieres, F., Terrisse, A.D., Sie, P., Payrastre, B., Guery, J.C., Bayard, F. and Gourdy, P. (2007) Understanding the Controversy about Hormonal Replacement Therapy: Insights from Estrogen Effects on Experimental and Clinical Atherosclerosis. Archives des Maladies du Coeur et des Vaisseaux, 100, 554-562.

[18] Mbourou Mensah, P., Leboueny, M.N., Essone, P., Maloupazoa Siawaya, A., Aboumegone Biyogo, O., Tadatsin, P., Mveang Nzoghe, A., Essamazokou, D., Mvoundza Ndjindji, O., Padzys, G.-S., et al. (2020) Age Associated Level of Estradiol (E2) and Progesterone (4) Influence IL-8 Response to Mycobacterium tuberculosis (Mtb) Antigens in Women. https://doi.org/10.21203/rs.3.rs-26657/v1

[19] Yasui, T., Uemura, H., Tomita, J., Miyatani, Y., Yamada, M., Kuwahara, A., Matsuzaki, T., Maegawa, M., Tsuchiya, N., Yuzurihara, M., Takeda, S. and Irahara, M. (2006) Association of Interleukin-8 with Hot Flashes in Premenopausal, Perimenopausal, and Postmenopausal Women and Bilateral Oophorectomized Women. Journal of Clinical Endocrinology \& Metabolism, 91, 4805-4808.

https://doi.org/10.1210/jc.2006-1100

[20] Malutan, A.M., Dan, M., Nicolae, C. and Carmen, M. (2014) Proinflammatory and Anti-Inflammatory Cytokine Changes Related to Menopause. PrZ Menopauzalny, 13, 162-168. https://doi.org/10.5114/pm.2014.43818

[21] Wickremasinghe, M.I., Thomas, L.H. and Friedland, J.S. (1999) Pulmonary Epithelial Cells Are a Source of IL-8 in the Response to Mycobacterium tuberculosis: Essential Role of IL-1 from Infected Monocytes in a NF-kappa B-Dependent Network. Journal of Immunology, 163, 3936-3947.

[22] Ameixa, C. and Friedland, J.S. (2002) Interleukin-8 Secretion from Mycobacterium tuberculosis-Infected Monocytes Is Regulated by Protein Tyrosine Kinases but Not by ERK1/2 or p38 Mitogen-Activated Protein Kinases. Infection and Immunity, 70, 4743-4746. https://doi.org/10.1128/IAI.70.8.4743-4746.2002

[23] Krupa, A., Fol, M., Dziadek, B.R., Kepka, E., Wojciechowska, D., Brzostek, A., Torzewska, A., Dziadek, J., Baughman, R.P., Griffith, D. and Kurdowska, A.K. (2015) Binding of CXCL8/IL-8 to Mycobacterium tuberculosis Modulates the Innate Immune Response. Mediators of Inflammation, 2015, Article ID: 124762. https://doi.org/10.1155/2015/124762

[24] Gungorduk, K., Ulker, V., Sahbaz, A., Ark, C. and Tekirdag, A.I. (2007) Postmenopausal Tuberculosis Endometritis. Infectious Diseases in Obstetrics and Gynecology, 2007, Article ID: 027028. https://doi.org/10.1155/2007/27028

[25] Erbay, G., Senol, G., Anar, C., Meral, A.R. and Tuzel, O. (2016) Relationship between Tuberculosis and Female Hormone Levels in Post-Menopausal Women. Southeast Asian Journal of Tropical Medicine and Public Health, 47, 78-83.

[26] Gameiro, C.M., Romao, F. and Castelo-Branco, C. (2010) Menopause and Aging: Changes in the Immune System-A Review. Maturitas, 67, 316-320.

https://doi.org/10.1016/j.maturitas.2010.08.003 
[27] Mishra, A. and Brinton, R.D. (2018) Inflammation: Bridging Age, Menopause and APOع4 Genotype to Alzheimer's Disease. Frontiers in Aging Neuroscience, 10, Article No. 312. https://doi.org/10.3389/fnagi.2018.00312

[28] Gameiro, C. and Romao, F. (2010) Changes in the Immune System during Menopause and Aging. Frontiers in Bioscience-Elite, 2, 1299-1303.

https://doi.org/10.2741/e190

\section{List of Abbreviations}

Estradiol: E2

GM-CSF: Granulocyte-macrophage colony-stimulating factor

IFN- $\gamma$. Interferon-gamma

IL- $1 \beta$ : Interleukin 1 beta

IL-10: Interleukin 10

IL-12: Interleukin 12

IL-2: Interleukin 2

IL-4: Interleukin 4

IL-5: Interleukin 5

IL-6: Interleukin 6

IL-8: Interleukin 8

Latent tuberculosis: LTB

Progesterone: $\mathrm{P} 4$

QuantiFERON-TB: QFT

TNF- $\alpha$ : Tumor necrosis factor-alpha

TB: Tuberculosis 